\title{
Kayıt Dışı Ekonomide Farklı Bir Boyut: Evden Çalışma
}

\author{
Osman GEYIK ${ }^{1}$ \\ Fatma TURNA ${ }^{2}$
}

Öz

\begin{tabular}{|c|}
\hline Makale Türü \\
\hline Araştırma Makalesi \\
\hline 28.07.2021 \\
\hline Kabul Tarihi \\
06.09.2021 \\
\hline DOI \\
\hline 10.53306/klujfeas.975314 \\
\hline JEL Kodu \\
\hline E2, E24, E26, 017
\end{tabular}

Kayıt dışı ekonomi ve kayıt dışı istihdam olguları özellikle günümüzde daha fazla konuşulan ve üzerinde tartışılan bir konu olarak ekonomik sistem içerisinde yer almaya başlamıştır. Dördüncü sanayi devrimi ile birlikte gelişen bilişim teknolojileri ve yaşanan salgın hastalıklar (Covid-19, Ebola, Kuş gribi gibi) kuruluşların iş yapma biçimini değiştirmesine sebebiyet vermiştir. Günümüzde, bilgi depolama ve telekomünikasyon sistemleri uzaktan çalışanlar arasında bilgi aktarımını kolaylaştırmıştır. Gelişen teknoloji, insanlara evden çalışma (home office) imkânı verirken, yaşanan salgın hastalıklar evden çalışmayı zorunlu kılmıştır. Ancak evden çalışmanın en önemli özelliği çalışanların görünmez oluşudur. Nitekim evden çalışan kişileri ispat etmek oldukça zordur ve bu şekilde çalışanlar istatistiklerde çoğunlukla ya ev kadını ya da işsiz olarak nitelendirilmektedir. Bu durum ise evden çalışanların kayıt dışı ekonomi zincirinin bir parçası olduğunu göstermektedir.Dolayısıyla bu çalışmada evden çalışma biçimi, kayıt dışı ekonomi ve kayıt dışı istihdam açısından incelenmiş ve bu kapsamda alınması gereken önlemlere yer verilmiştir.

Anahtar sözcükler: Kayıt dışı ekonomi, kayıt dışı istihdam, Covid-19, evden çalışma

1 Sorumlu Yazar: Arş. Gör. Dr., Dicle Üniversitesi, İktisadi ve İdari Bilimler Fakültesi, Maliye Bölümü, Maliye Teorisi Anabilim Dalı, osmangeyik@gmail.com, ORCID: 0000-0001-9885-9638

2 Arş. Gör. Dr., Hakkari Üniversitesi, İktisadi ve İdari Bilimler Fakültesi, Maliye Bölümü, Mali Hukuk Anabilim Dalı, fatmaturna86@gmail.com, ORCID: 0000-0002-9400-4795 


\title{
A Different Aspect in The Informal Economy: Working From Home
}

\author{
Osman GEYIK ${ }^{3}$ \\ Fatma TURNA 4
}

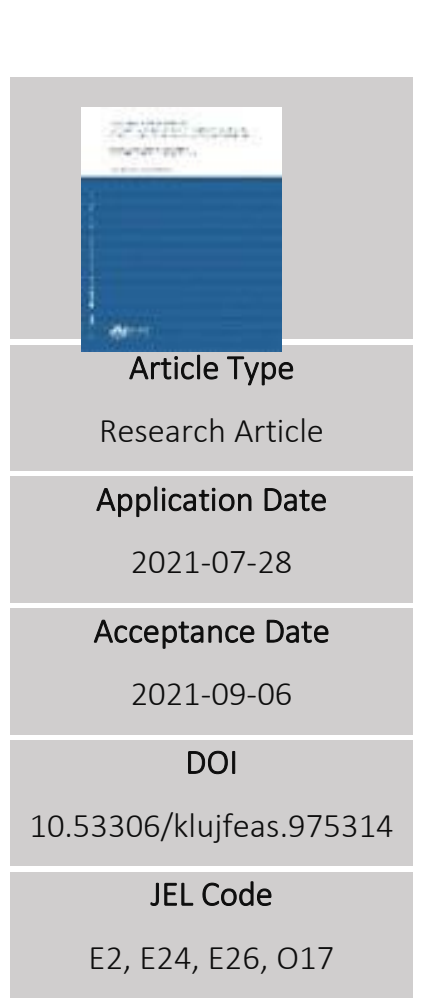

\begin{abstract}
Informal economy and informal employment have started to take more place in the economic system, and have been discussed more and more each day. Information technologies advancing with the fourth industrial development and recent outbreaks (COVID-19, Ebola, avian flu, etc.) changed the way institutions do business. Today, information storage and telecommunications systems have facilitated the transfer of information among remote employees. Advancing technology allows people to work from home (home office), while outbreaks have forced them to do so. But the most important aspect of working from home is that the employees have become invisible. As a matter of fact, it is quite difficult to prove those working from home, and this is why, employees are often described in statistics as either homemakers or unemployed. This goes to show that those working from home are a part of the informal economy. Therefore, this study discusses working from home from the perspective of the informal economy and informal employment and covers the measures to be adopted in this context.

Key words: Informal economy, informal employment, Covid-19, working from home
\end{abstract}

3 Corresponding Author: Res. Assist. Dr., Dicle University, Faculty of Economics and Administrative Sciences, Department of Public Finance, Department of Public Finance Theory, osmangeyik@gmail.com, ORCID: 0000-00019885-9638

4 Res. Assist. Dr., Hakkari University, Faculty of Economics and Administrative Sciences, Department of Public Finance, Department of Fiscal Law, fatmaturna86@gmail.com, ORCID: 0000-0002-9400-4795 


\section{Giriş}

Kayıt dışı ekonomi ve onun bir parçasını oluşturan kayıt dışı istihdam ekonomik işleyişi bozarak ekonomik ve sosyal yaşamı olumsuz yönde etkilemektedir. Kayıt dışı istihdamın en önemli olumsuz etkisi kamu gelirleri üzerinde yarattığı azaltıcı etki olarak kabul edilebilir. Bu azalma işverenlerin sigorta primlerini yatırmaması ve diğer vergisel yükümlülüklerden kaçınmasıyla ortaya çıkmaktadır. Bu negatif etki bütçe dengesinin bozulmasına neden olmaktadır. Bütçe dengesinin bozulması ise kamuyu yeni kaynak arayışına itmekte dolayısıyla borçlanma ya da para basımı yolu tercih edilmektedir. Söz konusu iki yöntemin de uzun vadede yüksek faiz ve yüksek enflasyonla ekonomiye zarar vereceği söylenebilir.

Kayıt dışı ekonominin sınırlı da olsa bazı olumlu yönlerinden bahsetmekte yarar vardır. Bu olumlu yönlerin başında sağlamış olduğu istihdam gelmektedir. Kayıt dışı istihdam vergilendirme konusunda devlete katkı sağlamasa da firmaların ekonomik faaliyetlerini artırmasına imkan tanıyacaktır. Ayrıca kayıt dışı istihdamın vergi gelirlerini azaltmasının yanında kişilerin harcanabilir gelirlerini artırması, tüketimi artırarak ekonomik faaliyetlerin canlanmasını sağlayacaktır (Kıldiş, 2000).

Kayıt dışı ekonomi, insanların yasalara güven duymamasına ve emek sömürüsüne neden olabilmektedir. Kayıt dışı olarak hiçbir sosyal güvencesi bulunmadan çalıştırılan bir iş̧̧inin mevcut yasalara güven duyması beklenen bir durum değildir. Bunun yanı sıra kayıt dışı ekonomiyle mücadelede devletlerin etkin bir rol oynamaması, kayıtlı olarak faaliyet gösteren kişilerin motivasyonlarını düşürecek, diğer taraftan da haksız rekabete neden olacaktır. Bu ve benzeri durumların varlığı kayıt dışı ekonomi ve daha spesifik olarak kayıt dışı istihdam konularının derinlemesine irdelenmesini gerekli kılmaktadır.

21. yüzyıl ile dijital dünyaya geçiş başlamış ve iş yaşamı farklı bir biçim almıştır.Bilişim teknolojileri sayesinde uzaktan çalışanlar arasında bilgi aktarımı hızla gelişmiştir. Teknolojinin bu şekilde ilerlemesi bir taraftan insanlara evden çalışma (ev/home ofis) imkânı sunmuş; diğer taraftan bu çalışma biçiminin ileriye yönelik taşınmasını sağlamıştır. Bu anlamda esnek çalışma modelinin temeli oluşmuştur. Artık insanlar normal mesaiyi ifade eden geleneksel çalışma modelinden ziyade çoğu zaman bir esnek çalışma modeli olan evden çalışmayı tercih etmektedir (Turna, 2021, s. 15).

Özellikle Covid-19 pandemisi, evden çalışma biçimini yaygınlaştırmıştır. Bu süreçte evden çalışma biçimi, insanlar için alternatif bir çalışma biçimi olmaktan çıkmış ve zorunlu hale gelen bir çalışma biçimine dönüşmüştür. Covid-19 krizi ile mücadelede alınan önlemler kapsamında evden çalışma modeli önemli bir adım olarak görülmüştür (Turna, 2020, s. 2215). Daha önceden ise evden çalışma, kuruluşlar tarafından kısmi olarak uygulanmıştı. Ancak başta Covid-19 olmak üzere yaşanan salgın hastalıklar bu dönemde, evden çalışma modelini çağımızın zorunlu bir gereği olarak karşımıza çıkartmıştır.

Öte yandan evden çalışma biçimi, ispatının zor olması bakımından iyi bir saklama mekanizması olarak görülmekte ve kayıtsı ekonominin önemli bir zincirini oluşturmaktadır. Bu anlamda evden çalışma vergi, sağlık ve sosyal sigorta pirimi gibi maliyetlerin kaybını oluşturmaktadır.Böyle bir ortamda ise mükelleflerin vergiye gönüllü uyumu azalmakta, gelir dağılımında denge bozulmakta, toplumsal değerler ve vergi bilinci aşınmakta ve istihdam 
yaratıc yabancı ve yerli yatırım gelişmemektedir (Hazine ve Maliye Bakanlığı, 2019, s. 2). Buna göre kayıt dışı istihdam, bir taraftan vergi hukukunu uygulanamaz kılmakta, diğer taraftan sosyal güvenlik ve iş hukukunu işlevsiz bırakmaktadır. Dolayısıyla bu çalışmada kayıt dışı ekonominin farklı bir boyutunu oluşturan evden çalışma biçimi esas alınmıştır. Bu doğrultuda evden çalışma kavramının, olumlu ve olumsuz yönleri incelenmiş ve evden çalışmanın kayıt dışı ile olan ilişkisi kayıt dışı istihdam çerçevesinde değerlendirilerek önerilerde bulunulmuştur.

\section{Kayıt Dışı Ekonomi ve Kayıt Dışı İstihdam}

Kayıt dışı ekonomi, içerisinde birçok boyutu barındırmaktadır. Kayıt dışı ekonomi, ekonomik faaliyetlerin kayıt altına alınmadan gerçekleştirilmesi ve bu nedenle bu faaliyette bulunanlara herhangi bir yükümlülük doğurmaması şeklinde tanımlanabilir. Kayıt dışı ekonomi, ekonomik düzenin işleyişine zarar veren bir olgu olarak değerlendirilmektedir. Kayıt dışı ekonomimin önemli bir ayağı ise kayıt dışı istihdamdır. Kayıt dışı istihdam, işverenlerin bünyelerinde çalıştırmış oldukları kişilerin çalıştıklarına dair bilgileri yetkili mercilerle paylaşmayarak bu kişilerin sosyal güvencesiz olarak çalışmalarını sağlamaları sonucu ortaya çıkan bir durumdur. Resmî kurumlara herhangi bir bildirimin yapılmamasıyla kayıt dışı istihdam söz konusu olmaktadır (Schneider, 1986; Önder, 2011; Huerta, 2020; Jahan vd., 2020).

Kayıt dışı olarak çalıştırılan kişilerin resmî kurumlara bildirilmemesi, işverenlerin sigorta primlerini ödemeyerek haksız kazanç sağlamalarına neden olurken; diğer taraftan sosyal güvenlik kurumunun dolayısıyla kamu gelirinde kayıpların ortaya çıkmasına neden olmaktadır (Enste ve Schneider, 2002). Sosyal güvenlik kurumun bütçesinde meydana gelen açıkların genel bütçeden karşılanması, vergisini ödeyen mükellefler ve diğer vatandaşlar için mali bir yük oluşturacaktır (Karaca ve Kaleli, 2019).

Kayıt dışı ekonomi çok çeşitli adlar altında ifade edilmektedir. Yer altı ekonomisi, gölge ekonomi, gizli ekonomi ve informel ekonomi bunlardan sadece birkaçıdır. Kayıt dışı ekonomi, mevcut istatistiki yollarla tahmini güç olan ve gayri safi milli hasıla (GSMH) hesaplamalarında kullanılmayan gelir yaratıcı faaliyetlerin tümünü ifade etmektedir. Bu tür faaliyetlerin kayıt altına alınamaması, ekonomik katkısının ölçülmesini de güç hale getirmektedir (Baldemir vd., 2005, s. 232).

Kayıt dışı ekonomi kavramı, ülke genelinde gerçekleştirilen ancak kayıt altına alınamayan faaliyetleri kapsarken, kayıt dışı istihdam sadece işgücündeki kayıt altına alınamayan istihdamı ifade etmektedir.

Uluslararası Çalışma Örgütü (International Labour OrganizationILO) tarafından 1970 yılında düzenlenen "Dünya İstihdam Programı" kapsamında hazırlanan Kenya Raporu'nda ilk defa ele alınan kayıt dışı istihdam kavramı, sonraki dönemlerde daha kapsamlı bir şekilde incelemelere konu olmuştur. Bu raporda, kayıt dışı istihdamın kayıtlı bir şekilde istihdam edilemeyen kişilerin kayıt dışı yollarla istihdam edilmesini sağladığı ifade edilmiştir (Kalaycı ve Kalan, 2017). 
Kayıt dışı ekonominin ortaya çıkışı çok çeşitli faktörlere dayanmaktadır. Gelişmiş ekonomilerde bu olgunun ortaya çıkışı vergi oranları ve yüküyle alakalı bir durum iken gelişmekte olan ülke ekonomilerinde ise daha çok gelir dağılımdaki adaletsizlikten kaynaklandığı ifade edilebilir (Dam vd., 2018). Enflasyon, gelir dağılımında adaletsizlik ve yoksulluk, vergi yapısı ve vergi oranlarının yüksekliği, vergisel ödevlerin fazlalığı ve mevzuatın karmaşıklığı, sürekli değişen yasalar, kamu alacaklarının tahsilinde var olan boşluklar, cezaların caydırıcı nitelikte olmaması, muafiyetler ve istisnaların kapsamının genişliği ve vatandaşların yasalara güven duymaması, vergi bilincinin oluşmaması ve mükelleflerin vergilere bakışı kayıt dışı ekonominin temel sebepleri arasında yer almaktadır.

"Kayıt Dışı İstihdamla Mücadele" projesinde kayıt dışı istihdamın nedenlerine ilişkin bilgiler yer almaktadır. Bu projeye ilişkin raporda kayıt dışı istihdamda, bürokratik işlemlerin fazlalığı, kurumlar arası koordinasyon eksikliği, denetim yetersizliği, işgücü maliyetlerinin yüksekliği, gelir dağılımındaki adaletsizlik, yoksulluk ve işsizlik, sigortalıların sosyal güvenlik hizmetlerinden hoşnutsuzluğu, bilgi ve bilinç eksikliği gibi durumlar kayıt dışı istihdamın ana nedenleri olarak belirtilmektedir (KADiM, 2006, s. 5).

İşücü maliyetlerinin yüksekliği ile ilişkili olarak vergi takozu (kaması) kavramının açıklanmasında yarar vardır. Vergi takozu ya da diğer bir ifadeyle vergi kaması, çalışan her iş̧̧i için işverenin devlete ödemekle yükümlü olduğu vergilerin ve sosyal güvenlik katkılarının toplamı şeklinde ifade edilebilir (Nar, 2015, s. 686).

Vergi takozu aşağıdaki formül yardımıyla hesaplanmaktadır (Aykın, 2017);

$$
\text { Vergi Takozu }=\frac{\text { Issçi İçin Ödenen Vergi,Sosyal Güvenlik Primi ve Benzerleri Toplamı }}{\text { İșçinin İșverene Toplam Maliyeti }} \times 100
$$

Tablo 1. Vergi Takozu - Türkiye ve OECD Ortalaması \% (2011-2020)

\begin{tabular}{lllllllllll}
\hline & 2011 & 2012 & 2013 & 2014 & 2015 & 2016 & 2017 & 2018 & 2019 & 2020 \\
\hline $\begin{array}{l}\text { OECD- } \\
\text { Ortalaması }\end{array}$ & 35.107 & 35.243 & 35.467 & 35.451 & 35.411 & 35.364 & 35.224 & 35.101 & 35.015 & 34.626 \\
\hline Türkiye & 37.028 & 37.127 & 37.357 & 38.086 & 38.186 & 38.241 & 38.898 & 39.247 & 39.577 & 39.664
\end{tabular}

Kaynak: OECD, 2021.

Tablo 1'de istihdam üzerindeki vergi yükü oranlarına yer verilmiştir. 2011-2020 yıllarına ait verilerin yer aldığı tabloda Türkiye'de istihdam üzerindeki vergi yükü oranının yıllar itibariyle artış gösterdiği gözlemlenmektedir. Ayrıca Türkiye'de istihdam üzerindeki vergi yükü OECD 
ülke ortalamasının üzerindedir. Bu durum kayıt dışı istihdamın en önemli nedenleri içerisinde yer almaktadır. İşverenin, yüksek maliyetlerden kaçınmak için kayıt dışı istihdam yolunu tercih etmesi karşılaşılan en temel sorunlardandır.

Türkiye'de kayıt dışı istihdam verileri, 10 Ağustos 2021 tarihinde Türkiye İstatistik Kurumu (TÜiK) tarafından yayınlanmıştır. Bu verilere göre Türkiye'de 2021 Mayıs ayında kayıt dışı olarak istihdam edilenlerin oranı, bir önceki yılın aynı ayına göre 1,6 puan azalarak \%27,9 olarak gerçekleşmiştir. Tarım dışı sektörde kayıt dışı çalışanların oranı bir önceki yılın aynı ayına göre 1,6 puan azalarak \%15,6 olarak gerçekleşmiştir (Tüik, 2021).

TÜik verilerine göre, kayıt dışı istihdam oranının bir önceki yılın aynı dönemine göre azalma göstermiş olmasına karşın bu oranın halen oldukça yüksek olduğunu ifade etmekte yarar vardır. Kayıt dışı olarak gerçekleştirilen faaliyetlerin GSYH hesaplamaları esnasında kullanılamaması ve kişilerin elde etmiş oldukları gelirlerin bilinmemesi kişi başına düşen gelirin doğru bir şekilde tespit edilmesinin önüne geçmektedir. Bu durum gelir artırıcı politikaların etkinliğini olumsuz bir şekilde etkilemektedir. Türkiye'de de kişi başına gelir artırıcı politikaların başarısız olmasının en önemli nedeninin kayıt dışı ekonomi olduğu söylenebilir (Dursun ve Dağcl, 2021, s. 40).

\section{Evden Çalışma Kavramı}

Evden çalışma", tarih boyunca farklı biçimlerde devamlılığını sürdürmüştür. "Ev" kavramı Sanayi Devrimi'ne kadar fırın evi, bira evi gibi ifadelerle kullanılmıştır. Aynı kavram 20. yüzyılda daha çok uyumak, yıkanmak, yemek pişirmek veya TV izlemek gibi anlamlara gelmiştir. Bu dönemde işyeri ile konut unsurunu birleştiren meskenler ise isimsiz kalmıştır (Workhome, 2017). Dolayısıyla oldukça eski bir yapıya sahip olan bu tür yapılar için işyeri ve konut unsurlarını içeren yeni bir kavramın oluşturulması gerekmektedir. Bu anlamda ev kavramı en basit ifadeyle insanların yaşadığı yeri ifade ederken işyeri ise ticari bir işin yapıldığı yeri ifade etmektedir. Bu tanımlara göre açık ve basit bir şekilde en uygun terim olarak "evden çalışma" kavramı oluşturulmuştur.

Evden çalışma genel olarak, "düşük beceri gerektiren faaliyetleri gerçekleştiren işçilerden, nitelikli, tecrübeli, teknolojik imkânları kullanan ve yönetimsel seviyede çalışmayı gerektiren geniş bir iş gücü potansiyelini kapsayan" bir çalışma biçimi olarak tanımlanmaktadır (Huws ve Podro, 1995, s. 2). Geleneksel anlamda evden çalışma, "kadınların yoğun olduğu, kadınların genellikle aile içerisinde ücretsiz çalıştığı, iş bölümünün toplumsal cinsiyete göre belirlendiği ve evin kadınlar tarafından ekonomik faaliyet alanına dönüştürüldüğü" (Erdut, 2011, s. 57) bir çalışma biçimidir. Modern anlamda evden çalışma ise "Teknolojinin gelişmesiyle özellikle hizmet sektöründe telefon ve internet üzerinde yapılan işlemlerin bilinen ofis mantığından çıkıp eve girmesi" (Duman, 2016) olarak ifade edilmektedir. Yine bir

\footnotetext{
${ }^{5}$ Evden çalışma kavramı, uzaktan çalışma kavramından farklıdır. Uzaktan çalışma iş yerinden uzakta bir yerde, evde veya başka bir yerde çalışmayı ifade ederken; evden çalışma ise iş faaliyetlerinin sadece evden gerçekleştirilmesini ifade etmektedir (Turna, 2021, s. 277).
} 
başka tanımda evden çalışma, "bir mal veya hizmet üretiminin kişi veya kişiler tarafından evden yürütülerek gelir elde edilmesi" olarak tanımlanmaktadır (Workhome, 2017).

ILO’nun 1996 tarihli 177 sayılı Evde Çalışma Sözleşmesi'nde ise evden çalışma kavramı, “... işverenin işyeri dışında kalan kişinin kendi evi veya kendi seçtiği diğer tesislerde, ücret için donanım, malzeme veya kullanılan diğer girdilerin kimin sağladığına bakılmaksızın işveren tarafından belirlenen bir ürün veya hizmet ile sonuçlanan çalışma" şeklinde tanımlanmaktadır (ILO, 1996). Bu tanımlar ev mesleğinin tanımında oldukça yaygın bir biçimde kullanılmaktadır.

Dolayısıyla evden çalışma, temel olarak konut unsurunun bir eklentisi olarak kullanılan ev tabanlı çalışma biçimini ifade etmektedir. Bir anlamda evden çalışma, konut unsurunun ikincil ve arızi olarak kullanımını oluşturmaktadır. Bu durum konutun özelliklerini değiştirmediği gibi dış yapısını da etkilememektedir (Workhome, 2017).

\section{Evden Çalışma Biçiminin Tarihi Gelişimi}

Evden çalışma modelinin öğretide oldukça eski bir tarihe sahip olduğu belirtilmektedir. Ortaçağ zamanında insanlar ve hayvanlar diktörtgen şeklinde dar, uzun, tek odalı ve tek katlı yerlerde yaşamışlardır. Yerleşim yerinin bir köşesinde kış gecelerinde hayvanlar kalmış, diğer köşesinde ise insanlar kalmıştır. Gün içerisinde yapılan bütün işler, bu bölmesiz ve tek alan içerisinde gerçekleşmiştir. Söz konusu alan yatak odası ve mutfak olarak kullanılırken aynı zamanda iplikçilik, terzilik, mandıra, dokuma ve kasaplık gibi ticari işler içinde kullanılmıştır (Workhome, 2017). O dönemlerde evde yaşam şekli, çalışma faaliyetlerinin odak noktasını oluşturmuştur. Terziler, dokumacılar, fırıncılar, ayakkabıcılar ve demirciler gibi meslekler Ortaçağ döneminin ilk ev işleri olarak görülmüştür (Reynolds ve Bibby, 2017).

18. ve 19. Yüzyılda ise Sanayi Devrimi ile birlikte fordist üretim modeline geçilmiştir. Bu sistem ile iş faaliyetleri yürüyen bantlarla gerçekleşmiş ve vasıfsız işçilerle yapılan bir üretim sistemi oluşmaya başlamıştır (Çakmak, 2004, s. 251). Bu dönemde iş dünyası daha merkezi bir konuma getirilmiş ve iş̧̧iler evden uzaklaştırılmıştır. Fabrika işleri, hem kadınlara hem de erkeklere büyük değişiklikler sunmuş, dışarıda emek harcama faaliyetlerini oluşturmuş ve dolayısıyla evden çalışma biçiminden uzaklaşılmıştır (Reynolds ve Bibby, 2017). Ancak bu sistem, üretim bakımından yetersiz olması, zaman kaybına neden olması ve belli alanlarda uzmanlık gerektirmesi nedeniyle dönemin ihtiyaçlarına cevap verememiştir (Çakmak, 2004, s. 251). Dolayısıyla 1970 'li yıllarda Post Fordist üretim sistemine geçilmiş ve böylece esnek çalışma biçimleri mevzuata girmeye başlamıştır. Atipik olarak nitelendirilen bu çalışma modeliyle, standart iş faaliyetinden vazgeçilmiş ve yeni bir esnek çalışma türü tanımlanmıştır (Aslan, 2016, s. 69).

20. yüzyılın sonunda ise fabrikalarda, ev ve iş yaşamının beraber oluşmasıyla birlikte, geleneksel evden çalışma biçimi ortaya çıkmıştır. Bu dönemde, gündelik hayatta "ev"in kaybolup, fabrikanın yaşamın tek mekânı haline geldiği, insanların çalıştıkları fabrikalarda yatıp kalktıkları, kölece "işçileşme" diye tabir edilen bir ara dönem yaşanmaya başlanmıştır (Topçuoğlu, 2012, s. 4-6). Türkiye'de ise 1980'lere kadar kırsalda "ücretsiz aile işçisi" olarak çalışan insanlar, kente göç ile birlikte ev işi yanında aile ekonomisine katkı sağlamak 
amacıyla merdivenaltı atölyelerde çalışmaya başlamıştır (Kaya ve Doğan, 2016, s. 1079). Ancak işçi örgütlenmesi ve sınıf mücadelesi ile kazanılan haklar sayesinde 20. Yüzyılın başlarında, evden çalışma mekânı her ne kadar birbirinden ayrılmış olsa da (Koç, 2005, s. 1), dijital çağın başlangıcı olarak nitelendirilen 21. Yüzyılda geleneksel evden çalışma, modern tarzda evden çalışma biçimine dönüşmüştür.

\section{Evden Çalışma Biçiminin Olumlu Etkileri}

Evden çalışma özellikle aile hayatı ile iş hayatını dengeleme bakımından kadınlara cazip gelmektedir. Ayrıca bu çalışma biçimi engelli bireyler için de uygun bir çalışma şeklidir (TiSK, 2003, s. 46). Bu yönüyle 21. yüzyılda evden çalışma biçimi, önemli bir çalışma biçimi olarak görülmektedir. Aile yaşamına daha fazla zaman ayırmak isteyen çalışanlar iş yerindense, evden çalışmayı tercih etmektedir (DiSK, 2003, s. 20).

2013 yılında Stanford Üniversitesi'nde yapılan bir araştırmaya göre şirkette çalışan bazı kişilere evden çalışma imkanı verilmiştir. Araştırma sonucuna göre evden çalışanların, \%9,5 daha fazla çalıştığı ve \%13 daha fazla üretken olduğu ortaya çıkmıştır (Krautzel, 2016). Araştırma verimlilik artışında çalışanların yaklaşık \%70'inin evde daha fazla çalışmaya bağ|ı olduğunu yaklaşık \%30'unun ise daha sessiz bir ortama bağlı olduğunu ifade etmiştir. Ayrıca şirket çalışan başına 9 ay boyunca 1900 dolar tasarruf etmiştir. Yine araştırmada evli çiftlerin, ebeveynlerin ve yaşlı çiftlerin evden çalışmayı daha çok tercih ettiği gözlemlenirken; sosyal hayatı daha çok ofis ortamına bağı olan gençlerde evden çalışma isteğinin daha düşük olduğu gözlemlenmiştir. Dolayısıyla her çalışan için evden çalışma biçiminin uygun olmadığı sonucuna ulaşılmıştır (Bloom, 2014).

Hollandada, yapılan bir araştırmada ise yolda geçen sürenin evden çalışanlara göre \%19 oranında bir maliyet oluşturduğunu, evden çalışanların diğer çalışanlara göre \%18 oranında daha yüksek bir gelire sahip olduğunu, işverenlerin evden çalışma ie birlikte maliyetlerini \%80'e kadar düşürebildiklerini (Graaff ve Piet, 2007) ve böylece evden çalışan başına 1500 dolar tasarruf elde ettikleri belirtilmiştir. Ayrıca evden çalışan kişilerin, evden çalışmayan kişilere göre ortalama ayda 4 saat daha fazla çalıştığı görülmektedir (Butler, 2007).

Diğer taraftan, evden çalışma insanlara maddi anlamda tasarruf imkânı sunduğu gibi zaman bakımından da tasarruf sağlamaktadır. Ayrıca evden çalışanların aile ile daha fazla vakit geçirmesi bakımından psikolojik faydalar sağladığı da gerçektir. Özellikle verimli bir zaman yönetiminin oluşturulması, trafikte harcanan zaman kayıplarının giderilmesi, hava kirliliğinin azalması, aileye harcanan zamanın artırılarak iş hayatının ve sosyal hayatın dengelenmesi, enerji tasarrufunun sağlanması gibi etkiler bu çalışma biçimine yönelik faydaların sadece birkaçını oluşturmaktadır (Şamlıoğlu, 2016). Evden çalışma biçiminin diğer olumlu etkileri ise aşağıda sıralanmaktadır (Duman, 2016; Global Workplace Analytics, 2017, s. 22; Workhome, 2017; Reynolds ve Bibby, 2017);

$\checkmark \quad$ Kurum ve kuruluşlar açısından ekonomiye katkı sunar.

$\checkmark$ istihdamı genişletir ve kalifiye eleman ihtiyaçlarını azaltır.

$\checkmark$ iş ve ev kullanımında alanların etkin bir şekilde kullanımını sağlar.

$\checkmark$ Teknolojik araç gereçlere yönelik maliyetleri azaltır.

$\checkmark$ Beyin göçünü yavaşlatır. 


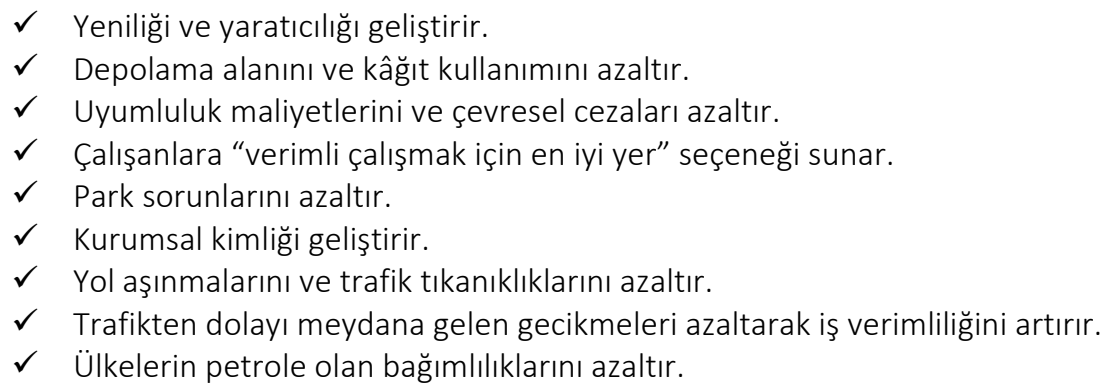

Bu faydalarından dolayı evden çalışma, şirketler kadar ülkeler tarafından da tercih edilmektedir. Birçok ülke evden çalışma modelini kullanarak herhangi bir ek maddi gider olmadan, genel/engelli istihdam oranlarını artırmakta, işsizlik oranını azaltmakta, kırsal bölgelerde ekonominin gelişimine katkı sağlamakta ve dar gelire sahip olan ailelerde refah düzeyini artırabilmektedir. Böylece evden çalışma ülkelerin mevcut sorunlarının giderilmesinde önemli bir strateji olarak görülmektedir (ikizler, 2012, s. 174; İnciroğlu, 2013, s. 41).

Ayrıca evden çalışma biçimi, istihdama yönelik yapılan göçleri, kalifiye eleman eksikliğini ve işgücü uyumsuzluğunu giderebilmektedir. Yine sınır ötesi işlem maliyetlerinin azaltılmasında, bölgesel anlamda istihdam popülâsyonlarını dengelemede ve iş gücü etkinliğinin artırılmasına katkı sağlayabilmekte ve bu nedenle ülkeler evden çalışma modelinden önemli ölçüde faydalanabilmektedir (Global Workplace Analytics, 2017, s. 5-6).

\section{Evden Çalışma Biçiminin Olumsuz Etkileri}

Evden çalışmanın olumlu yönleri olduğu gibi olumsuz yönleri de bulunmaktadır. Bu olumsuz yönler, "uzak işin yakın tehlikeleri" olarak ifade edilmektedir (Tutar, 2007, s. 131). Evden çalışma, kişinin gerçek anlamda eve ait olma duygusunu zedelemektedir. Esasında ev olarak nitelendirilen ortam, ev olmaktan çıkmıştır ama işyerinin işlevlerini ise tam olarak karşılamamaktadır. Böyle bir ev ortamında çalışan kişi, kendi bütünlüğünün farkına varamadığı gibi kişiliğini de ortaya koyamamaktadır. Dolayısıyla ailenin geleneksel anlamda bir ferdi konumunda olan kişi, geleneksel rolünden uzaklaşmış ve bir çalışana dönüşmüştür (Tutar, 2007, s. 134-135).

Evden çalışmak, çalışanın zihni ve psikolojisi açısından olumsuz durumlar oluşturabilmektedir. Evden çalışanlar, bu anlamda yalnızlık unsurunu diğer çalışanlara göre fazlasıyla yaşayan bireyler olarak karşımıza çıkmaktadır (Tutar, 2007, s. 131). Evden çalışan yalnız yaşıyorsa, çalışma saatleri boyunca insanlarla iletişim kuramamaktadır. Kaldı ki çalışan, ailesi ile birlikte olsa bile; ayrı bir ofiste çalışabilmek adına kendini kapatabilmekte ve ihtiyaç duymuş olduğu iletişimden mahrum kalabilmektedir. Evden çalışma bir anlamda yalnızlığı veya soyutlanmayı beraberinde getirdiği gibi fiziksel olarak rahatsızlıkları da beraberinde getirebilmektedir. Yalnızık, kronik çapta, kişiyi hayal kırıklığına, kariyer tükenmesine ve depresyona maruz bırakabilirken (Alton, 2017); diğer taraftan fiziksel rahatsızlıklar bakımından, fıtık, kireçlenme ve kambur durma gibi sorunları ortaya çıkartabilmektedir. Bu durum ise evden çalışanın, hem ev ortamına hem de iş ortamına olan 
aidiyet duygusunu zedelemekte ve çalışan kişiyi asosyal bir yapıya büründürmekte ve daha çok sağlık sorunlarıyla karşılaşabilmesine sebebiyet vermektedir (Turna, 2021, s. 79).

Ayrıca evden çalışan kişi, telefon, bilgisayar ve faks makinesi gibi sesini duyduğu, mesajını aldığı, ancak etkileşimli bir iletişim kuramadığı sanal bir işi yapmaktadır (Tutar, 2007, s. 134). Dolayısıyla işyerinde doğal olarak gerçekleşen sosyal bağlantılar da kaybedilmektedir. Yüz yüze bir toplantıda, insanların hisleri, olaylara karşı verdiği tepkiler kolay bir şekilde anlaşılabilir iken; sanal bir toplantıda, herkesin ofis odasında akıllarından geçeni anlamak veya beden dilini çözmek zorlaşmaktadır (Camenisch, 2014). Bu nedenle kurum veya şirketler, hiçbir görüşmenin yüz yüze görüşmeden daha yararlı olamayacağı gerçeğinden (Active, 2016) hareketle evden çalışma biçimini eleştirmektedir. Evden çalışmaya ilişkin diğer olumsuz etkiler ise aşağıda sıralanmaktadır (Harrison, 2001; Kavi ve Koçak, 2010, s. 76; Krautzel, 2016; Schiff, 1979; Tutar, 2007, s. 131-132);

$\checkmark$ Evden çalışma, fazla dikkat dağıtıcı ve çalışmaya elverişli sessiz bir mekân olmaması nedeniyle pratik olmayan bir çalışma biçimidir.

$\checkmark \quad$ Evden çalışma, işyerindeki hiyerarşik düzenden uzak olması sebebiyle evden çalışanın gelişimi ve kariyeri üzerinde olumsuz bir etki oluşturmaktadır.

$\checkmark \quad$ Evden çalışanlar, yüz yüze bir etkileşim gerçekleştiremediklerinden dolayı inovasyon azalmakta ve şirketin kültürü zarar görmektedir.

$\checkmark$ Düşük performans gösteren çalışanlar, denetçiler tarafından fark edilememektedir.

$\checkmark \quad$ Evden çalışanların, işyerleri ile olan bağları ağ düzeyinde kaldığı için kurumsal bağ|ılık hissiyatları olumsuz etkilenmektedir.

$\checkmark$ İşverenler, evden çalışan personeller için bir takım prosedürler ve kurulum sistemleri bakımından yatırım maliyetlerine katlanmakta ve bu maliyetler çoğunlukla işverenler tarafından önemli bir risk olarak görülmektedir.

$\checkmark$ Evden çalışma çalışanın, doğal bio-ritminin bozulmasına ve fiziksel/psikolojik sağlığının olumsuz etkilenmesine sebebiyet vermektedir.

Diğer taraftan evden çalışma, zaman yönetimini ve öz disiplini gerekli kıldığı için herkese uygun bir çalışma biçimi olarak görülmemektedir. Birçok işveren evden çalışanları denetleme zorluğundan dolayı bu çalışma biçimine karşı direnç göstermektedir (Schiff, 1979). Ancak bu çalışma modelinde olumsuz durumların kişiden kişiye değişiklik gösteriyor olması ve şirketlerin fayda maliyet analizini gözetmesi gibi nedenlerden dolayı bu çalışma modeli, şirketler ve kurumlar tarafından kabul edilmektedir (Active, 2016). Evden çalışma politikasını iyi yöneten bir işveren, uzun vadede verimli sonuçlar elde edebilmektedir (Turna, 2021, s. 82).

\section{Evden Çalışma ve Kayıt Dışı İstihdam Illişkisi}

Kayıt dışı çalışma biçimlerinden özellikle ülkelerde en yaygını, evden çalışma modelidir. (Topçuoğlu, 2012, s. 4-6). Bu anlamda evden çalışma, çalışanları görünmez kılmaktadır. Yapılan faaliyetlerin kim tarafından ve nerede yapıldığını anlamak oldukça zordur (DiSK, 2003, s. 14-20). 
Diğer taraftan geleneksel olarak evden çalışanlar, genellikle ev kadınlarıdır. Esasında evden çalışma, kadınların ev kadını olarak görülmesini kolaylaştırmaktadır. Bu şekilde çalışanlar, kendini çalışan olarak görmemekte ve işgücü istatistiklerinde bile ya "ev kadını" ya da "işsiz" olarak sayılmaktadır. Örneğin; evden çalışan bir kadına, evdeki çocuklar dâhil komşuları bile yardım etmekte, kadınlar ise bu durumu yardım veya aile içi dayanışma olarak ifade etmekte ve dolayısıyla yardım edenler çalıştıklarını veya iş yaptıklarını düşünmemektedir (DISK, 2003, s. 14-20).

$\mathrm{Bu}$ anlamda geleneksel evden çalışma biçimi, çalıştığının farkında olmayan ve kendini ev kadını olarak tanımlayan bir iş̧̧i grubunu oluşturmaktadır. İstatistiklerde, geleneksel evden çalışanlar diye gözüken kitle, sadece kendini bu şekilde tanımlayan kısıtlı bir grup olmakta ve bu durum istatistiklerde dahi görülmemektedir. Bu ortam, kayıt dışı alanın oluşmasına zemin hazırlamaktadır. Kayıt dışıı̆ıın giderek üretimi saklayan yapısı için "evin güvenliği" iyi bir perde arkası olarak kullanılmaktadır. Bu anlamda evden çalışma kayıt dışı üretim zincirinin bir parçasını oluşturmakta ve bu zincirin yoğunlaştığı yerde ise özellikle geleneksel anlamda evden çalışan kadınlar yer almaktadır (Topçuoğlu, 2010, s. 113-126).

Diğer taraftan gelişmiş ülkelerde evden çalışanların önemli bir kısmını göçmen olarak bilinen çalışanlar oluşturmaktadır. Örneğin; İngiltere'de Asyalı çalışanlar, Avustralya'da Vietnamlı çalışanlar evden çalışanlar arasında önemli bir yer tutmaktadır. Göçmenlerin karşı karşıya olduğu pek çok sorun arasında evden çalışma sorunu ise kaybolup gitmektedir. Nitekim çalıştıkları ülkelerdeki sistemleri ve hakları yeterince bilmemeleri, evden çalışan göçmenlerin görünmez kalmalarına yol açmaktadır. Ayrıca, göçmenler birçok para olarak ödenen haklardan "çalışmamaları" şartıyla yararlanabilmektedir. Bu da evden çalışan göçmenlerin, kendilerini çalışan olarak beyan etmek yerine gizlemeyi tercih etmelerine yol açmaktadır (DiSK, 2003, s. 21).

Günümüzde ise evden çalışmada, her ne kadar evden çalışan erkek oranı (kadın \%52, erkek \%48) azımsanmayacak bir oranda olsa bile hala kadınların tercih ettiği bir çalışma modeli olarak karşımıza çıkmaktadır (Global Workplace Analytics, 2017, s. 1-27). Nitekim artık evden çalışma, parça başı iş yapma, engelli bir bireye bakma, bir başka evde gündelik işleri (temizlik, yemek gibi) yapma veya yaşlı ve çocuk bakımı gibi sürekli nitelikte olan birçok işi kapsamaktadır. Bu anlamda evden çalışma kendi içinde çok sayıda çalışma türünü kapsayan bir çalışma modeli olarak karşımıza çıkmaktadır (Dereli, 2018).

Diğer taraftan evden çalışma, çalışanlarını görünmez kılması nedeniyle çalışanların objektif nitelikteki haklarını saklı tutmaktadır. Dolayısıyla kayıt dışılığın üretimi saklayan yapısı içerisinde ev kavramı, iyi bir saklama mekanizması olarak görülmekte ve kayıt dışı alanın oluşmasına zemin hazırlamaktadır (Topçuoğlu, 2010, s. 113-126).

Kayıt dışı kapsamında evden çalışmada, işverenin kısmi anlamda bir sorumluluğu bulunmaktadır. Neticede evden çalışanların, rıza gösterdiği bir ortam söz konusudur. Bu anlamda kayıt dışı istihdamı azaltmak adına öncelikle işgücü katma değerin artırılması, kayıtlı istihdamın teşvik edilmesi ve sonrasında çok sıkı denetimlerin yapılması gerekmektedir (Türkay, 2019, s. 129). Ayrıca kayıt dışı kapsamında evden çalışmanın, sosyal 
güvenlik açıdan sosyal güvenlik hukuku ile vergisel açıdan mali hukukla, çalışma ve denetim açısından ise idare ve iş hukuku ile yakından ilgili olduğu görülmektedir. Dolayısıyla kayıt dışı istihdamı önlemeye yönelik mevzuatlar yetersiz kalmakta ve bu doğrultuda ilgili mevzuatların yeniden düzenlenmesi gerekmektedir (Erdut, 1998, s. 100-101).

\section{Sonuç}

Öğretide evden çalışmanın olumlu ve olumsuz yönlerinin olduğu belirtilmektedir. Ancak evden çalışmanın olumlu yönlerinin olumsuz yönlerden fazla olması ve olumsuz etkilerin çalışandan çalışana farklılık göstermesi bu çalışma modelini tercih edilebilir kılmaktadır.

Diğer taraftan zaman ve öz disiplin yönetimine sahip olamayan çalışanlar, evden faaliyet yürütmemelidir. Evden çalışan bir kimsenin, kişisel zaman ile profesyonel zaman sınırlarını iyi ayarlaması gerekmektedir. Evden çalışan, zamanını iyi yönetemiyorsa bu durum iş verimliliği açısından risk oluşturmaktadır. Bu nedenle öğretide bu konuda herhangi bir istatistiksel bir veri bulunmamasına rağmen çoğu işverenin, personelini göz önünde bulundurmak adına evden çalışma modeline sıcak bakmadığı belirtilmektedir.

Ancak bazı ülkelerde istihdamın artırılması, kaynakların israf edilmemesi ve çevrenin korunması adına bu çalışma modeli tercih edilmekte ve bu nedenle şirketlerin veya kurumların bazı personel gruplarının belli bir oranının evden çalışması zorunlu kılınmaktadır. Nitekim evden çalışma biçimini iyi manada yönetenler, iş verimliliği açısından uzun vadede etkin sonuçlara ulaşabilmektedir. Ancak evden çalışma konusunda, işin gereklerine uzakta bile olsa en iyi uyumu sağlayabilecek personellerin tercih edilmesi önemlidir. Bu anlamda evden çalışma biçimini yönetmenin, evden çalışma imkânının sunulmasına göre daha etkili olduğu ifade edilebilir.

Buna göre kayıt dışı istihdam, bir yandan iş hukukunu ve sosyal güvenlik hukukunu uygulanamaz kılar iken bir yandan da vergi hukukunu işlevsiz bırakmaktadır. Bu kapsamda ülkemizde evden çalışmaya ilişkin mevzuat düzenlemeleri yetersiz kalmaktadır. Konuyla ilgili özellikle Covid-19 krizi nedeniyle 10 Mart 2021 tarihinde Uzaktan Çalışma Yönetmeliği yayınlanmıştır. Ancak uzaktan çalışma kavramı, işyerinden uzakta bir yerde, evde veya iş yerinde çalışmayı ifade ederken; evden çalışma, iş faaliyetlerinin sadece evden gerçekleştirilmesi gerektiğini ifade etmektedir. Bu anlamda çıkarılan yönetmelik evden çalışma modeli kapsamında yetersiz kalmaktadır. Özellikle evden çalışmaya ilişkin vergi hukukumuzda özel bir düzenlemenin bulunması gerekmektedir. Dolayısıyla evden çalışma kapsamında hem devlet, hem işveren, hem de çalışan açısından dengelerin sağlanması ve bu kapsamda yapılan hukuki düzenlemelerin sağlam bir zemine oturtulması şarttır. Böylece kayıt dışı ekonominin bir türü olan kayıt dışı istihdam ile mücadele kapsamında önemli bir adım atılmış olunacaktır. 


\section{"Kayıt Dışı Ekonomide Farklı Bir Boyut: Evden Çalışma" Başlıklı Makalenin Araştırma ve Etik Beyanı Bilgileri}

\begin{tabular}{|c|c|}
\hline & $\begin{array}{c}\text { Bu çalışma "Araştırma ve Yayın Etiği" değerlerine uygun olarak } \\
\text { hazırlanmıştır }\end{array}$ \\
\hline Bilgilendirme & $\begin{array}{l}\text { Çalışma herhangi bir bildiri veya tez benzeri çalışmadan üretim } \\
\text { değildir. }\end{array}$ \\
\hline $\begin{array}{l}\text { Yazar Çıkar } \\
\text { Çatışması Beyanı }\end{array}$ & Çalışmada herhangi bir çıkar çatışması bulunmamaktadır. \\
\hline $\begin{array}{l}\text { Yazar Katkı Oranı } \\
\text { Beyanı }\end{array}$ & Her iki yazarın da çalışmaya katkısı \%50 - \%50 olarak belirlenmiştir. \\
\hline Teşekkür & Çalışmada teşekkür gerektiren bir durum bulunmamaktadır. \\
\hline $\begin{array}{l}\text { Etik Kurul Onay } \\
\text { Belgesi }\end{array}$ & Çalışmada etik kurul onayı gerekmemektedir. \\
\hline
\end{tabular}

\section{Kaynakça}

Active. (2016, Ocak 12). The Advantages and Disadvantages of Remote Working. https://www.activeukltd.com/advantages-disadvantages-remote-working/ Erişim Tarihi: 25 Temmuz 2021.

Alton, L. (2017, Mayıs 25). Is Working From Home Making You Miserable?.Nbcnews. https://www.nbcnews.com/ Erişim Tarihi: 22 Temmuz 2021.

Aslan, H. (2016). Ev-Eksenli Çalışan Kadınların Sosyal ve Ekonomik Hayatlarına İlişkin Bir Saha Araştırması: Denizli İli Örneği. Fe Dergi, 8(1), 69-90.

Aykın, H. (2017). Vergi Takozu (Kaması) Nedir? Güncel Vergi Takozu Oranları, https://vergidosyasi.com/2017/10/05/vergi-takozu-kamasi-nedir-guncel-vergitakozu-oranlari/ Erişim Tarihi: 15 Temmuz 2021.

Baldemir, E., vd. (2005). Türkiye'de Kayıt Dışı Ekonominin MIMIC Model ile Tahminlenmesi. Süleyman Demirel Üniversitesi Iktisadi ve Idari Bilimler Fakültesi Dergisi, 10(2), 231243.

Bloom, N. (2014, Ocak-Şubat). To Raise Productivity, LetMoreEmployeesWorkfrom Home. Harvard Business Review.https://hbr.org/2014/01/to-raise-productivity-let-moreemployees-work-from-home Erişim Tarihi: 23 Ağustos 2021. 
Butler, E. S. Cheryl A., Susan W. (2007, Nisan). DoesTelecommuting ImproveProductivity?.Communication of the ACM, 50(4), 101103.

Camenisch, J. (2014, Mayıs 30). How Working From Home Might Be Getting You Down. Upwork.https://www.upwork.com/blog/ Erişim Tarihi: 22 Temmuz 2021.

Çakmak, U. (2004). Esnek Üretim Sistemi: İstihdama Etkisi ve Toyota Örneği. Ekonomik Yaklaşım Dergisi. 15(52-53), 235-253.

Dam, M. M., Ertekin, Ş., Kızılca, N. (2018). Türkiye'de Kayıt Dışı İstihdamın Boyutu: Ekonometrik Bir Analiz. Dokuz Eylül Üniversitesi Iktisadi Idari Bilimler Fakültesi Dergisi, 33.1 (2018): 293-318.

Dereli, N. (2018, Mayıs 3). Evde Çalışma Nedir? Ev Hizmetlerinde Çalışanların Hakları Nelerdir?.Irade Gazetesi. http://www.sivasirade.com/kose-yazilari/ Erişim Tarihi: 15 Temmuz 2021.

DiSK. (2003). Ev-Eksenli Çalışanlar ve Örgütlenmeleri. İstanbul: Birleşik Metal-iş Yayınları.

Duman, O. (2016, Aralık 25). Evden Çalışmanın Hayatımızdaki ve Kanundaki Yeri. http://www.ceviriblog.com/2016/12/25/evden-calismanin-hayatimizdaki-vekanundaki-yeri/ Erişim Tarihi: 4 Temmuz 2021.

Dursun, H. , Dağcı, A . (2021). Kayıt Dışı Ekonomiye Karşı Halkın Bilinçlendirilmesi Bağlamında Alınması Gereken Önlemler. Aksaray Üniversitesi iktisadi ve Idari Bilimler Fakültesi Dergisi , 13 (2) , 35-48. DOI: 10.52791/aksarayiibd.889049.

Enste, D., Schneider F. (2002). Hiding in The Shadows: The Growth of The Underground Economy (No. 30). International MonetaryFund, Washington D.C.

Erdut, T. (1998). Yeni Teknolojilerin Iş̧ Ilişkileri Üzerindeki Etkisi. İzmir: Türk Ağır Sanayii ve Hizmet Sektörü Kamu İşverenleri Sendikası (TÜHIS).

Erdut, T. (2011). Toplumsal Cinsiyet Bakımından Evde Çalışma. Çalışma ve Toplum Dergisi, (2), s. 55-81.

Global WorkplaceAnalytics. (2017). 2017 State of Telecommuting in the U.S Emloyee Workforce.https://cdn.thepennyhoarder.com/wp-content/uploadsErişim Tarihi: 16 Temmuz 2021.

Graaff, T., Piet R. (2007). Substitution Between Working at Home and Out-Of-Home: The Role of ICT and Commuting Costs. Science Direct.https://www.sciencedirect.com/ Erişim Tarihi: 11 Mayıs 2021.

Harrison, N. (2001). Teleworking from Home. Ariadne. http://www.ariadne.ac.uk/ Erişim Tarihi: 25 Temmuz 2021.

Hazine ve Maliye Bakanlığı. (2019). Kayıtdışı Ekonomiyle Mücadele Stratejisi Eylem Planı (2019-2021).https://www.gib.gov.tr Erişim Tarihi: 08 Mayıs 2021. 
Huerta, A. (2020). Viewpoint: An Education in The Informal Economy. Planning, 86(1), 13. Available at: www.scopus.com.

Huws, U., Podro, S. (1995). Employment of Homeworkers: Examples of Good Practice. Analytica Social and Economic Research Ltd. Working Paper. Geneva: International Labour Office. http://staging.ilo.org/public/libdoc/ilo/1995/95B09 358 engl.pdfErişimTarihi: 05 Temmuz 2021.

ILO. (1996). 177 Sayılı Evde Çalışma Sözleşmesi (Çev. Alp, E. Sönmez, Ö. A.). Iş Hukuku ve iktisat Dergisi, 23(5-6), Ağustos - Kasım 2011, s. 16-27.

İkizler, M. (2012). Türk Hukukunda Esnek Çalışma. Ankara: Adalet Yayınevi.

İnciroğlu, L. (2013). Çalışma Hayatında Esnek Çalışma Uygulamaları. İstanbul: Legal Yayınevi.

Jahan, I., Pavlik, J.B., Williams, R.B. (2020). Is the Devil in the Shadow? The Effect of Institutional Quality on Income. Review of Development Economics, 00, 1-21. https://doi.org/10.1111/rode.12691..

KADiM. (2006). Kayıt Dışı İstihdamla Mücadele (KADiM) Projesi ille Illgili 2006/28 Sayılı Başbakanlık Genelgesi , T.C. Resmi Gazete, Sayı: 26309, Tarih: 4 Ekim 2006. https://www.resmigazete.gov.tr/eskiler/2006/10/20061004-13.htm Erişim Tarihi: 26 Temmuz 2021.

Kalaycı, C., Kalan, E. (2017). Türkiye'de Kayıt Dışı İstihdamla Mücadele Politikalarının Analizi. Uluslararası Ekonomi İsletme ve Politika Dergisi, 1(1), 17-34.

Karaca, C., Kaleli, E. (2019). Türkiye'de Kayıt Dışı İstihdama İlişkin Çözüm Önerileri. Sosyal Politika Çalışmaları Dergisi, 19(44), 769-792.

Kaya, M., Doğan, B. B. (2016). Esnek Çalışma Modeli: Ev Eksenli Çalışma. Elektronik Sosyal Bilimler Dergisi, 15(58), s. 1069-1099.

Kavi, E., Koçak, O. (2010). Bilgi Toplumunda Evden Çalışmanın Etik Boyutu. Sosyal Siyaset Konferansları, (59), s. 69-88.

Kıldiş, Y. (2000), “Kayıt Dışı Ekonominin Ulusal ve Uluslararası Boyutu ... Dokuz Eylül Üniversitesi Sosyal Bilimler Enstitüsü Dergisi, Cilt: 2, Sayı: 2.

Koç, S. E. (2005). Kadın Girişimciler Kavramı ve Serbest Meslek Mensubu Kadın Girişimcilere Ilişskin Konya Ilinde Uygulamalı Bir Araştırma (Yüksek Lisans Tezi). Sosyal Bilimler Enstitüsü, Konya.

Krautzel, J. (2016, Mart 8).The Ups and Downs of Telecommuting for Businesses and Workers. Nexxt. https://www.nexxt.com/articles/ Erişim Tarihi: 17 Temmuz 2021.

Nar, M. (2015). Ücret Gelirleri Üzerindeki Vergi Yükü: Vergi Takozu Uygulaması, InternationJournal of Human Sciences, 12(1), 685-705. 
OECD. (2021). Tax Wedge. OECD Database, https://data.oecd.org/tax/tax-wedge.htm Erişim Tarihi: 16 Temmuz 2021.

Önder, I. (2011). Kayıt Dışı Ekonomi ve Vergileme. İstanbul Üniversitesi Siyasal Bilgiler Fakültesi Dergisi, (23-24). 241-254.

Reynolds, B. W., Bibby, A. (2017, Ocak 30). The Complete History of WorkingfromHome.Flexjobs. https://www.flexjobs.com/blog/post/completehistory-of-working-from-home/ Erişim Tarihi: 18 Temmuz 2021.

Schiff, F. W. (1979, Eylül 2). Working at Home Can Save Gasoline. The Washington Post. https://www.washingtonpost.com/archive/ Erişim Tarihi: 22 Temmuz 2021.

Schneider, F. (1986). Estimatingthe size of the Danish Shadow Economy Using the Currency Demand Approach: An Attempt. Scandinavian Journal of Economics, 88(4): 64368.

SGK. Kayıtdışı İstihdam Genel Bilgi. http://www.sgk.gov.tr/ Erişim Tarihi: 18 Temmuz 2021.

Şamlıoğlu, H. (2016, Nisan 12). Yükselen Trend; Evden Çalışma. http://www.teakolik.com/yukselen-trend-evden-calisma/Erişim Tarihi: 17 Temmuz 2021.

TiSK. (2003). Iş Kanunu Tasarısı ve AB Uygulamaları. Ankara: TisK Yayınları.

Topçuoğlu, A. R. (2010). Kapitalizm ve Ataerkillik Enformel Alanda Nasıl Eklemlenir?, Bilinçli Saklama ve Saklayarak Değersizleştirme Mekanizmalarının Ev Esnekliçalışmada İşleyişi. Dedeoğlu, S. Yaman, M. Ö. (Ed.), Kapitalizm, Ataerkillik, ve Kadın Emeği: Türkiye Örneği (s. 81-133). İstanbul: Sosyal Araştırmalar Vakfı.

Topçuoğlu, R. A. (2012). Küreselleşme ve Üretimin Esnekleşmesi Sürecinde Kadın Emeği. Türk Tabipleri Birliği Mesleki Sağlık ve Güvenlik Dergisi,12(44).

Turna, F. (2020). ABD Vergi Hukuku Açısından Ev Eksenli Çalışma Modeli. Legal Mali Hukuk Dergisi, 16(188), s. 2215-2244.

Turna, F. (2021). ABD Modeliyle Karşılaştırmalı Olarak Vergi Hukukunda Evden Çalışma. Ankara: Seçkin Yayınevi.

Tutar, H. (2007). Katı Olan Her "iş" Sanallaşıyor veya İşgörenin Artan Yalnızlığı Üzerine: Kuramsal Bir Yaklaşım. "Işs, Güç” Endüstri Ilişskileri ve Insan Kaynakları Dergisi, 9(2), s. 116-141.

Tüik. (2021). İşgücü İstatistikleri. https://data.tuik.gov.tr/Bulten/Index?p=IsgucuIstatistikleri-Mayis-2021-37489 Erişim Tarihi: 16 Temmuz 2021.

Türkay, I. (2019). Kayıt Dışı Ekonomik Faaliyetlerde Bulunmak/Vergi Kaçırmak Anayasal Bir Suç Mudur?.Vergi Dünyası Dergisi, 39(458), s. 124-136.

Workhome. A BriefHistory of theWorkhome. http://www.theworkhome.com/historyworkhome/ Erişim Tarihi: 26 Temmuz 2021. 


\title{
A Different Aspect in The Informal Economy: Working From Home
}

\author{
Osman GEYIK
}

Fatma TURNA

\section{Extended Abstract}

The informal economy and informal employment, which forms part of it, disrupt economic functioning, but in some cases have positive effects on economic and social life. The most important negative effect of informal employment is that it reduces public revenues. This reduction occurs when employers do not pay insurance premiums and avoid other tax obligations. This negative effect disrupts the budget balance. Disruption of this balance pushes the public sector to look for new resources, leading to either borrowing or printing money. It can be said that both of these methods will injure the economy in the long term through high interest payments and inflation. It would not be wrong to say that the informal economy would cause people to have lack of trust in the law and lead to labor exploitation. A worker working informally without any social security is not expected to have trust in applicable law. In addition, failure to play an active role in combating the informal economy will reduce the motivation of formal employees and, on the other hand, will lead to unfair competition. The existence of these and similar situations requires an indepth study of the informal economy and, more specifically, informal employment. It can be said that informal economy or employment can be tolerable in some cases up to a certain level to maintain economic activity and keep the economy alive. This is valid in the labor market and the manufacturing sector.

On one hand, the 21st century has been defined as the beginning of the digital world, while it has also been described as the century of outbreaks (avian/swine flu, Ebola, COVID-19, etc.). The COVID-19 crisis has shown that the digital world is not as it seems. Outbreaks and advancing information technologies have led to the beginning of the digital age. While the digital age gave people the opportunity to work from home, the pandemic forced people to do so. Perhaps, working from home has been experienced the greatest during the COVID19 crisis.

Working from home has continued throughout history in different ways. In the early times, this form of work manifested itself more as traditionally while in the later periods, it manifested itself as a much more modern-style. Therefore, the concept of working from 
home, in its most general sense, is defined as a form of work that refers to a wide-ranging employment network that includes labor-oriented workers, using experience and technological opportunities, and administrative management.

However, the most important aspect of working from home is that it renders employees invisible. Employees working this way are often considered unemployed in statistics. As a matter of fact, working from home is considered a good concealing mechanism as it is difficult to prove and forms an important chain of the informal economy. In such an environment, taxpayers' tax compliance is reduced, tax awareness and social values are eroded, and unfair distribution of income emerges.

Although working from home means comfort from the point of view of employees, it leads to the popularization of informal employment along with a lack of rules and irregularity. Informal employment constitutes the informal economy. The informal economy has negative consequences in all areas of working life and the social order of life. The informal economy does not only lead to the loss of insurance premiums and tax losses, but also creates unfair competition. In such an environment, there is no opportunity for foreign and domestic investment that can create a workforce.

Therefore, this study examines the model of working from home, which constitutes a different aspect of the informal economy. In this sense, this study focuses on the informal economy, informal employment, and the concept of working from home, analyzes the negative and positive aspects of working from home, evaluates the correlation between this working method and informal economy from the perspective of informal employment, and provides recommendations.

Informal employment, on the one hand, makes labor law and social security law unenforceable; on the other hand, it leaves tax law dysfunctional. In this context, legislation on working from home in Turkey is inadequate. In particular, there is no specific regulation in the tax law related to working from home. Therefore, within the scope of working from home, it is necessary to strike a balance from the point of view of both the state and the employer and the employee, and the legal regulations introduced in this framework should be based on solid ground. 